\title{
Determinants of investor expectations and satisfaction. A study with financial professionals
}

\author{
Rene Schwaiger ${ }^{\mathrm{a}}$, Michael Kirchler ${ }^{\mathrm{a}, \mathrm{b}, *}$, Florian Lindner ${ }^{\mathrm{c}}$, Utz Weitzel ${ }^{\mathrm{d}, \mathrm{e}}$ \\ a Department of Banking and Finance, University of Innsbruck, Universitätsstrasse 15, Innsbruck 6020, Austria \\ ${ }^{\mathrm{b}}$ Department of Economics, Centre for Finance, University of Gothenburg, Vasagatan 1, Gothenburg 40530, Sweden \\ ${ }^{\mathrm{c}}$ Max Planck Institute for Research on Collective Goods, Kurt-Schumacher-Str. 10, Bonn 53113, Germany \\ d Utrecht University School of Economics, Kriekenpitplein 21-22, EC Utrecht 3584, The Netherlands \\ e Institute for Management Research, Radboud University, Thomas van Aquinostraat 5.1.26, Nijmegen 6525, The Netherlands
}

\section{A R T I C L E I N F O}

\section{Article history:}

Received 12 October 2018

Revised 25 February 2019

Accepted 20 March 2019

Available online 8 April 2019

\section{JEL classification:}

G02

G11

D03

C93

\section{Keywords:}

Investor satisfaction

Price expectations

Financial professionals

Experimental finance

Investor behavior

\begin{abstract}
A B S T R A C T
We investigate determinants of price expectations and satisfaction levels of financial professionals and students. In experiments with 150 professionals and 576 students, we systematically vary price paths according to the final return (positive or negative) and the way in which the final return is achieved (upswing followed by downswing or vice versa). Professionals show the most optimistic price expectations and are most satisfied if assets fall in price first and then recover. In addition, professionals' price expectations are highest after positive returns. Among students, qualitatively similar patterns emerge, but professionals' price expectations are less prone to framing effects.
\end{abstract}

(C) 2019 The Author(s). Published by Elsevier B.V. This is an open access article under the CC BY license. (http://creativecommons.org/licenses/by/4.0/)

\section{Introduction}

Imagine the following investment situation. You held an asset for one year yielding 5\%, but ex-post you realize that the stock was up $+20 \%$ mid-term. At the same time, your friend reports of an investment giving him a return of $5 \%$ as well, after a trough of $-15 \%$ halfway through the year. Although you and your friend ended up with the same returns, the question arises whether both of you will be equally happy about your investments and whether your experience from the past year will influence your price expectations of your stock? In a world full of homines economici (Thaler and Sunstein, 2008), investors will be equally satisfied and focus solely on future cash flows when assessing the future potential of the

\footnotetext{
We thank the editor Nobuyuki Hanaki, two anonymous referees, Jürgen Huber and Stefan Zeisberger for very valuable comments on earlier versions of the paper. We are grateful to Achiel Fenneman, Patricia Leitner, Alexander Wolf, and MC Jan Zatocil for their excellent research assistance. We particularly thank all participating financial institutions and professionals for their excellent collaboration and for their enthusiasm. Lastly, we gratefully acknowledge financial support from the Austrian Science Fund (FWF START-grant Y617-G11, SFB F63), Radboud University, and the Swedish Research Council (grant 2015-01713). This study was ethically approved by the IRB of the University of Innsbruck.

* Corresponding author at: Department of Banking and Finance, University of Innsbruck, Universitätsstrasse 15, 6020 Innsbruck, Austria.

E-mail addresses: rene.schwaiger@uibk.ac.at (R. Schwaiger), michael.kirchler@uibk.ac.at (M. Kirchler), florian.r.lindner@gmail.com (F. Lindner), u.weitzel@uu.nl (U. Weitzel).
} 
stocks. In this paper, we will analyze whether experienced and highly skilled financial professionals, but also students, act in such a way.

Following the framework of neoclassical economic theory, decision-makers should exclusively focus on economic outcomes and ignore the way in which these outcomes have been achieved. However, framing effects, which should not influence decisions, are indeed relevant for decision-makers (see, among others, Arrow, 1982; Dreber et al., 2013; Tversky and Kahneman, 1981; 1986).

Moreover, framing effects also seem to be of importance to investment decisions. Chen and Rao (2002), for instance, investigate whether the evaluation of a sequence of events in which an initial event is unexpectedly reversed impacts a decision maker's happiness. In particular, the authors run a series of experiments with student subjects and find that a gain after a corresponding loss in a coin tossing game makes subjects happier compared to a loss after a corresponding gain. The authors attribute their findings to changes of the reference point towards the direction of the outcome of the first coin toss. In addition, Baucells et al. (2011) contribute to these findings in an investment frame. The authors run investment game experiments with student subjects and present past price sequences. Among other patterns, in a few sequences an increase precedes a decrease (dashed hope) and in some other sequences a decrease precedes an increase (false alarm). The authors report differences in the self-stated neutral selling price conditional on the past price sequence. Hence, reference points (neutral selling prices) are upwardly (downwards) revised after initial gains (losses), supporting the findings in Chen and Rao (2002) that initial gains with subsequent losses make people less satisfied because of increased reference points.

A recent study by Grosshans and Zeisberger (2018) extends the findings of Chen and Rao (2002) and Baucells et al. (2011) by examining the effect of how returns are achieved on satisfaction levels and expectations. The authors run experiments with student subjects and participants from MTurk (Amazon Mechanical Turk) and they show that self-reported satisfaction levels with hypothetical investments are significantly affected by the way in which final returns are achieved. More specifically, participants were exposed to graphical illustrations of different stock price paths over a period of 12 months. The authors demonstrate that investors are significantly more satisfied with stocks exhibiting decreasing and subsequently recovering price paths compared to stocks with an opposite price pattern. Furthermore, the authors report that stocks with down-up paths are associated with more optimistic price expectations compared to stocks with the inverse price pattern.

Nevertheless, the question remains open as to whether the results of Grosshans and Zeisberger (2018) also hold for financial professionals. This question is important, as professionals might be less prone to such framing effects, given years or decades of experience with investment decisions (Kirchler et al., 2018a; 2018b). Moreover, professionals are central to the functioning of financial markets, and hence their behavior has far-reaching consequences for society, as demonstrated by the last financial crisis. Recent lab-in-the-field experiments with non-student subjects have shown the importance to study the behavior of professionals in various areas. In political science, Sheffer et al. (2018) has shown that incumbents in Belgium, Canada, and Israel are as or more subject to common choice anomalies when compared to non-politicians-i.e., they exhibit a stronger status-quo bias, similar framing effect biases and a stronger tendency to stick to decisions with sunk costs compared to subjects from general population samples. In finance, various scholars propose the hypothesis that experience of finance professionals in real-world markets can eliminate or reduce certain biases (e.g., List, 2004). Among others, recent experimental evidence shows that this is not necessarily the case as professionals apply behavior in line with prospect theory as well (Abdellaoui et al., 2013), react stronger to rank incentives compared to non-professionals (Kirchler et al., 2018b), and show herd behavior similar to student subjects (Cipriani and Guarino, 2009). In this paper, we shed more light on professionals' behavior by answering the question of whether professionals' price expectations and satisfaction levels are driven by the way (the frame) in which investment returns were achieved, providing us with evidence with respect to professionals' susceptibility to investment-related framing effects.

Consequently, we closely replicate the study of Grosshans and Zeisberger (2018) by conducting lab-in-the-field experiments with 150 professionals from various Northern and Central European countries. Importantly, we mainly recruited professionals who regularly engage in investment decisions, such as financial advisors, traders, fund managers, portfolio and investment managers, and analysts. Professionals in our sample are on average 39 years old and have on average 13 years of experience in the industry, whereby $86 \%$ of professionals are male. Moreover, we ran laboratory experiments with 576 students with a matched gender ratio from the University of Innsbruck, who serve as a control group and as a proxy for the behavior of laypeople. ${ }^{1}$ We decompose price expectations and satisfaction with the investments (on a 9 point Likert scale) of both subject pools to separate the contributions of price path developments and the level of returns, respectively. Specifically, we set up four treatments using a within-subjects design, differing in (i) the final return over the past 12 months (either $+10 \%$ or $-10 \%$ ) and in (ii) the price paths through which the final returns were achieved (decreasing prices followed by increasing prices or vice versa). To provide our subjects with the information about past prices, we show static graphs of one-year price charts. As major outcome variables we elicited subjects' price expectations for the upcoming 12 months and investors' satisfaction levels on a 9-point Likert scale. First, we find that professionals and students believe in short-term trend continuation, since their price expectations are significantly more optimistic for stocks with price paths that first dropped and then subsequently recovered, holding final returns constant. Additionally, we show that price expectations of professionals and students are significantly more optimistic after positive returns compared to negative returns.

\footnotetext{
1 The results in Grosshans and Zeisberger (2018) show no systematic difference in the behavior of laypeople and students, hence, students can serve as a kind of proxy for laypeople in this setting.
} 
Importantly, when analyzing absolute differences in price expectations between stocks with a down-up path and stocks with an up-down path (when holding final returns constant), we find that professionals' price expectations are more consistent compared to the ones of students. This indicates that professionals' price expectations are less influenced by the frame. Second, we report that the satisfaction levels of professionals and students are affected by the stock price path itself. Specifically, we observe that, for a given return, professionals and students prefer stocks with decreasing and subsequently recovering prices compared to stocks with the opposite pattern. Third, we report that realized returns have a stronger impact on price expectations and satisfaction levels for both subject pools than the shape of the stock price paths. Hence, our study shows that preferences for stock price paths are relevant determinants for price expectations and investment satisfaction even for well-trained and experienced professionals and it also shows that professionals' behavior only differs moderately from the behavior of inexperienced students.

Our study contributes to the literature in three ways. First, we contribute to the literature on sequential preferences. For example, Loewenstein and Prelec (1993) find that individuals prefer higher utility levels later in time when focusing on series of events-a pattern which is referred to as "negative time preferences". In general, there is a body of literature showing that the order of information has an impact on decision-making in various domains (Alexander and Ang, 1998; Bergus et al., 1998; Haugtvedt and Wegener, 1994). Chapman (1996) explains such preferences with reference point dependency. An ascending series of salaries, wealth, or stock prices is thus perceived as a series of gains, leading to a higher utility compared to a descending series. More generally, Blanchard et al. (2014) argue that preferences over sequences are hardwired into our brain as part of evolutionary processes, by pointing out that sequence dependency also occurs in other primates like monkeys.

Second, we add to the strand of literature analyzing trend-chasing behavior. ${ }^{2}$ For private investors, Sirri and Tufano (1998) and Choi et al. (2010), among others, show that the past performance of mutual fund managers is a predictor of fund inflows in the upcoming year (i.e., fund inflows are a convex function of past fund performance compared to peers). More specifically, a substantial body of literature directly investigates trends in price expectations and in investment behavior either with empirical data (e.g., Greenwood and Shleifer, 2014), or by applying heterogeneous agent models (see, e.g., Hommes, 2006; Hommes and in 't Veld, 2017). A significant fraction of heterogeneous models applies a chartist/fundamentalist approach, allowing agents to switch between trend-following behavior (chartist) and fundamentalist strategy. We add to this line of literature by showing that not only laypeople (students), but even high-skilled and well-trained financial professionals believe in short-term trend continuation, as their price expectations are higher following down-up price paths compared to up-down paths (when final returns are held constant). ${ }^{3}$

Third, we add to the literature dealing with the behavior of financial professionals, which is still in its infancy. Some studies attribute deviations from neoclassical theory to a lack of market experience (e.g., List, 2003; 2004), while other studies (e.g., Cherian and Jarrow, 1998; Ferraro et al., 2005) argue that economic theory might become self-fulfilling when economically more advanced individuals adopt the theory as a normative benchmark. Results of studies analyzing the role of professionals' experience on their behavior are at best mixed, as professionals' behavior is not systematically closer to theoretical optima than the behavior of laypeople. For instance, professionals exhibit a high degree of myopic loss aversion (Haigh and List, 2005), react strongly to rank incentives (Kirchler et al., 2018b), show herd behavior similar to student subjects (Cipriani and Guarino, 2009), apply behavior in line with prospect theory (Abdellaoui et al., 2013), and are overconfident with respect to their forecasting abilities (Deaves et al., 2010; Menkhoff and Schmeling, 2013; Pikulina et al., 2017). However, professionals are apparently less prone to anchoring than students (Kaustia et al., 2008), can better discern the quality of public signals in information cascades (Alevy et al., 2007), and produce price bubbles less likely and with lower magnitude in laboratory asset markets (Weitzel et al., 2018). Turning to framing effects, it appears that such effects are not only present in non-finance-related domains (Druckman, 2001; Gächter et al., 2009) or in individuals with little financial experience (Benartzi and Thaler, 1999; Bosman et al., 2015), but also among financial planners (Roszkowski and Snelbecker, 1990). To the best of our knowledge, evidence for framing effects in investment decisions among investment professionals is scarce, thus, our study tries to narrow this gap.

\section{Study design}

In this experiment, we confronted subjects with different stocks price paths. Subjects were asked to imagine that they had purchased the stocks for themselves one year ago. ${ }^{4}$ We presented four price paths in a within-subjects design, where the subjects were exposed to the paths (see Fig. 1) in a quasi-randomized way. More precisely, we implemented 8 unique pre-defined sequences, which differed in the ordering of the four stocks. Participants were allocated randomly to one of the 8 sequences. The treatments, named DUP, DUN, UDP, and UDN, indicate the unique combinations of pathways and final returns of the stocks; “down-up-positive," “down-up-negative," “up-down-positive," and "up-down-negative," respectively.

\footnotetext{
2 One could, of course, argue that our findings are not surprising, assuming that a certain fraction of professionals might use some kind of technical analyses or momentum strategies. However, we have no data on how many professionals are technical analysts or momentum traders and whether they used these techniques in the experiment. We thank one referee for pointing this out and consider it for further research.

${ }^{3}$ In a loosely related study, Cohn et al. (2015) provide evidence that risk attitudes of professionals are influenced by past price paths. The authors find that professionals' risk taking is significantly enhanced in a financial boom prime and reduced in a financial bust prime. Nevertheless, König and Trautmann (2018) do not report these effects for students.

${ }^{4}$ Detailed instructions can be found in the Appendix.
} 

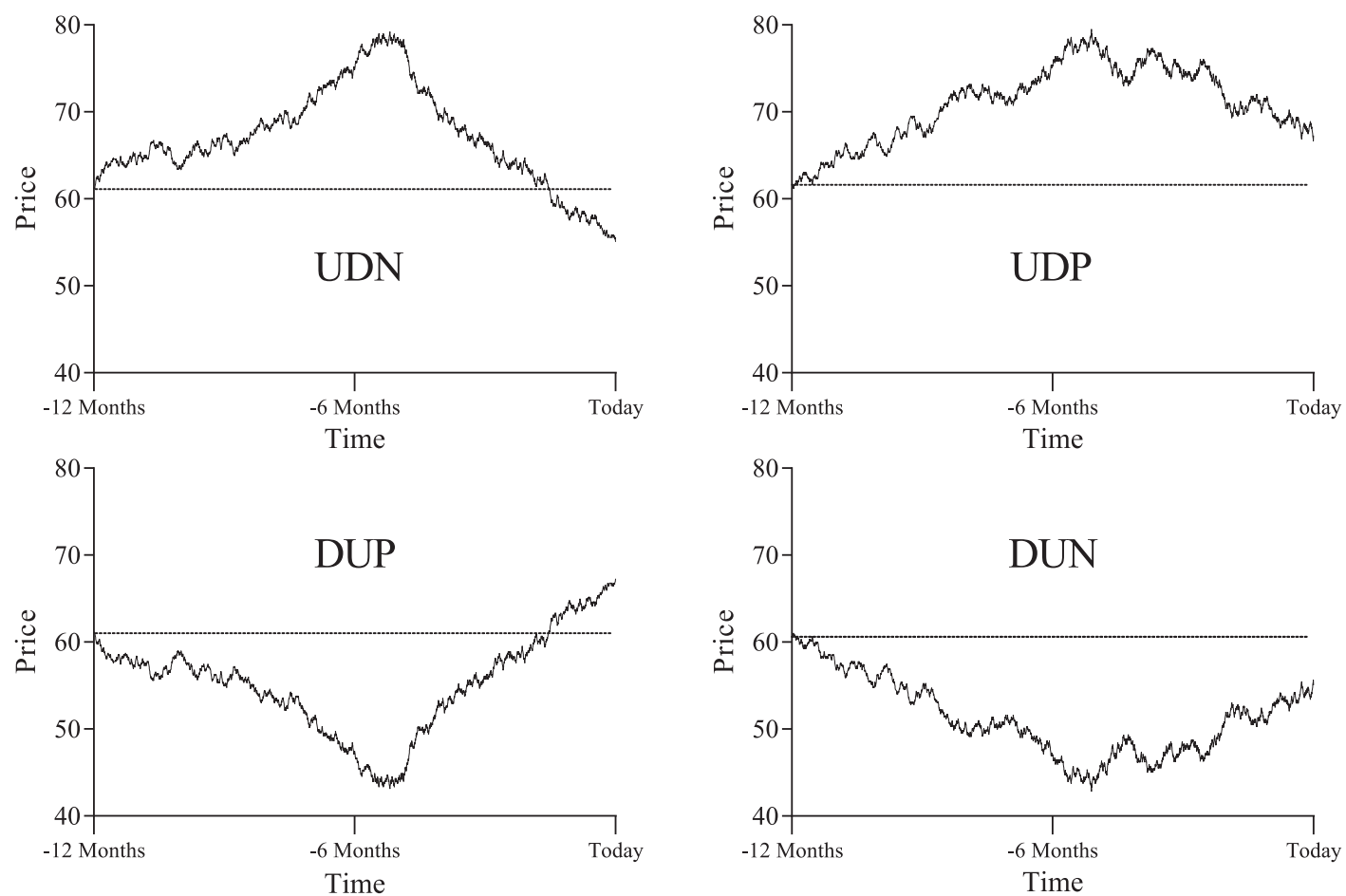

Fig. 1. This figure shows all four stock price paths (treatments). Each price path has a starting value of 61 . The price paths were presented to the subjects in sequential order. The chart on the top left shows the up-down price pattern with negative final return (UDN), the chart on the top right indicates the up-down price pattern with positive final return (UDP), and both charts in the bottom panels represent the mirrored versions, exhibiting a down-up price pattern (DUP and DUN, respectively).

All price paths were partially simulated and based on Grosshans and Zeisberger (2018). ${ }^{5}$ The reasoning behind using partially simulated price charts was that it enabled us to have full control over the combination of relevant characteristics of the path like the starting price, the final price, the return, the standard deviation per price change, the minimum price, the price-peak and the turning points. This was also the reason why the paths were not based on a stochastic process such as a random walk. More specifically, prices were normalized to a starting price of 61 , with the maximum and minimum prices set at $+30 \%$ and $-30 \%$ of the starting price, respectively. The scaling of the $y$-axes was standardized to facilitate the comparability between the charts. As in Grosshans and Zeisberger (2018), extreme values were reached after seven months, and the prices of each of the four stocks changed 2520 times in total, with final returns being either $+10 \%$ or $-10 \%{ }^{6}$ As outlined in Fig. 1, there existed two pairs of stocks that are vertically mirrored versions of each other, characterized by identical levels of volatility. To guarantee that the participants were not aware of the partial symmetry of the stocks, the 8 pre-defined sequences were designed in a way to ensure that symmetric pairs were never successive. For each price path, the subjects were asked about forecasts of the stock prices in one year to capture future price expectations and, additionally, they had to state individual satisfaction levels ranging from -4 ("very unsatisfied") to 4 ("very satisfied"). See the instructions in the Appendix for the exact wording in the experiment. In addition, subjects had to state the prices at which they felt neutral about selling their stocks, the 95\% confidence intervals for their price expectations, and a recommendation on whether to hold or sell the stock (4-point Likert scale ranging from very likely sell to very likely hold). Furthermore, we implemented a modified three-question cognitive reflection test (CRT), which was applied as a potential explanatory variable for patterns in price expectations and satisfaction levels (see Kirchler et al., 2018b and the Appendix for further details). ${ }^{7}$

For the experiments with the professionals, we booked a conference room on location, set up our mobile laboratory, and invited the professionals. Our mobile laboratory is similar to the EconLab at the University of Innsbruck (see the

\footnotetext{
${ }^{5}$ Because of time constraints when running lab-in-the-field experiments with professionals, we applied four out of the six price paths of Grosshans and Zeisberger (2018).

${ }^{6}$ Around these pre-determined values, normally distributed random numbers with a standard deviation per price change of $0.4 \%$ of the starting price were drawn to complete the price paths.

7 We have opted for the CRT rather than for other cognitive tests (e.g., Raven's Advanced Progressive Matrices), because recent experimental studies have shown that cognitive reflection skills explain superior performance in financial decision making (Corgnet et al., 2018). The CRT is based upon the dual-process theory framework (Kahneman, 2013) and thereby measures reflective and correct answers (System 2) vs. automatic and false responses (System 1) in reasoning tasks. Also outside financial decision making, the CRT is relevant even if it is controlled for other cognitive skills and personality factors (Toplak et al., 2011). Furthermore, higher cognitive reflection has been associated with a lower propensity for behavioral biases (Oechssler et al., 2009).
} 
Appendix for sample pictures of both labs). It consists of laptops and partitions surrounding each participant, which guarantees the same conditions as in regular experimental laboratories. We mainly recruited members of professional associations and societies, ensuring that most sessions were populated with professionals from different institutions. The experiment was programmed and conducted using z-Tree (Fischbacher, 2007). Experimental sessions with students were carried out in the EconLab at the University of Innsbruck. As outlined in the top panel of Table 1, the average age of the professionals was 39.0, and they have been working in the industry for an average of 13.2 years. Table A3 in the Appendix shows the specific job functions of the professionals in our sample and the different asset classes they are primarily working with. The major fraction of professionals self-reported to work in the fields of financial advice/consulting (26.40\%), fund management/trading (16\%), investment and portfolio management (25\%), and analyses (6.25\%). The major asset classes they work with are relatively equally split, however, equity and fixed-income are slightly more prominent. Moreover, a substantial part (86\%) of professionals in our subject pool was male. In terms of our sample compositions, we aimed at roughly matching the gender ratio of the professional sample to our student sample, and therefore, our student sample consisted of $77 \%$ male subjects. On average, students were 23 years of age and from various fields of studies such as natural sciences, medical sciences, and social sciences, whereby $36 \%$ of all students were enrolled in programs in management and economics. Like in Grosshans and Zeisberger (2018), our experimental subjects received a fixed payment for their participation. In particular, we paid an appearance fee of 18 (6) Euro for each professional (student). We followed previous literature and did opt for a flat payment, since it is difficult to incentivize subjectively stated satisfaction levels. Even though there might be less noise in experiments with performance-based incentives, we believe to have enough statistical power to overcome this issue (Smith and Walker, 1993). Overall, the participants took on average 10 minutes to complete the experiment.

\section{Results}

\subsection{Investor expectations}

Table 1 offers descriptive results for both subject pools, and Fig. 2 depicts the average price expectations of professionals and students across treatments, split into the gain and loss domains. ${ }^{8}$ Furthermore, results of paired-sample $t$-tests between the treatments and subject pools are presented in Table A1 in the Appendix.

Table 1

Summary statistics of both subject pools. Treatment DUP indicates the down-up price pattern with positive final return, while UDP stands for the treatment with an up-down price pattern with positive final return. Treatments DUN and UDN represent the mirrored versions, exhibiting negative final returns, respectively. For each price path, subjects were asked about expectations of the stock prices in one year (variable EXPECTATIONS) and they had to state individual satisfaction levels (variable SATISFACTION) ranging from -4 ("very unsatisfied") to 4 ("very satisfied").

\begin{tabular}{|c|c|c|c|c|}
\hline & \multicolumn{2}{|c|}{$\begin{array}{c}\text { (1) } \\
\text { Professionals }(N=150)\end{array}$} & \multicolumn{2}{|c|}{$\begin{array}{c}(2) \\
\text { Students }(N=576)\end{array}$} \\
\hline & Mean & $\mathrm{sd}$ & Mean & sd \\
\hline \multicolumn{5}{|l|}{ CHARACTERISTICS } \\
\hline Age & 39.02 & 9.71 & 22.89 & 2.93 \\
\hline Experience & 13.15 & 8.49 & - & - \\
\hline CRT & 1.85 & 1.01 & 1.82 & 1.09 \\
\hline \multicolumn{5}{|l|}{ EXPECTATIONS } \\
\hline Down-Up Positive (DUP) & 70.91 & 7.91 & 70.20 & 43.21 \\
\hline Up-Down Positive (UDP) & 67.84 & 7.86 & 65.40 & 11.80 \\
\hline Down-Up Negative (DUN) & 61.79 & 6.02 & 61.53 & 9.91 \\
\hline Up-Down Negative (UDN) & 57.71 & 9.72 & 55.71 & 11.14 \\
\hline \multicolumn{5}{|l|}{ SATISFACTION } \\
\hline Down-Up Positive (DUP) & 1.99 & 1.56 & 2.24 & 1.49 \\
\hline Up-Down Positive (UDP) & 1.05 & 1.80 & 1.00 & 1.73 \\
\hline Down-Up Negative (DUN) & -0.92 & 1.79 & -0.85 & 1.89 \\
\hline Up-Down Negative (UDN) & -2.45 & 1.52 & -2.42 & 1.69 \\
\hline
\end{tabular}

Age and industry experience are measured in years. The variable EXPECTATIONS is measured in Euro, the variable SATISFACTION ranges from -4 to 4 , and CRT ranges from 0 to 3 .

\footnotetext{
8 Table 1 also shows average CRT scores, which do not significantly differ between professionals and students (average of 0.03 , 1.85 (Prof $N=150$ ) vs. 1.82 (Students $N=576$ ); two-sample $t$-test; $p=0.3852$ ). There can be multiple explanations for this. This result is in close connection to the CRT scores of professionals and students in Kirchler et al. (2018a) and Kirchler et al. (2018b). Hence, it seems that students at the University of Innsbruck (on a Bachelor and Masters level) score close to sophisticated financial professionals from high-level areas, when holding the gender ratio constant. It also seems that these students score very well compared to students at other universities (Frederick, 2005). The non-existing difference between professionals and students might not come as a big surprise as our professionals mainly hold university degrees. Moreover, these results extend the findings from Thoma et al. (2015), who show that traders (a highly sophisticated sub-group among professionals) score significantly better than non-finance employees. The CRT score of 2.49 of traders (i.e., the original questions from Frederick (2005) were taken and hence match with our questions) is also clearly higher than the one of the finance professionals in our sample, indicating that traders are outstanding in their cognitive reflection ability within the finance industry.
} 


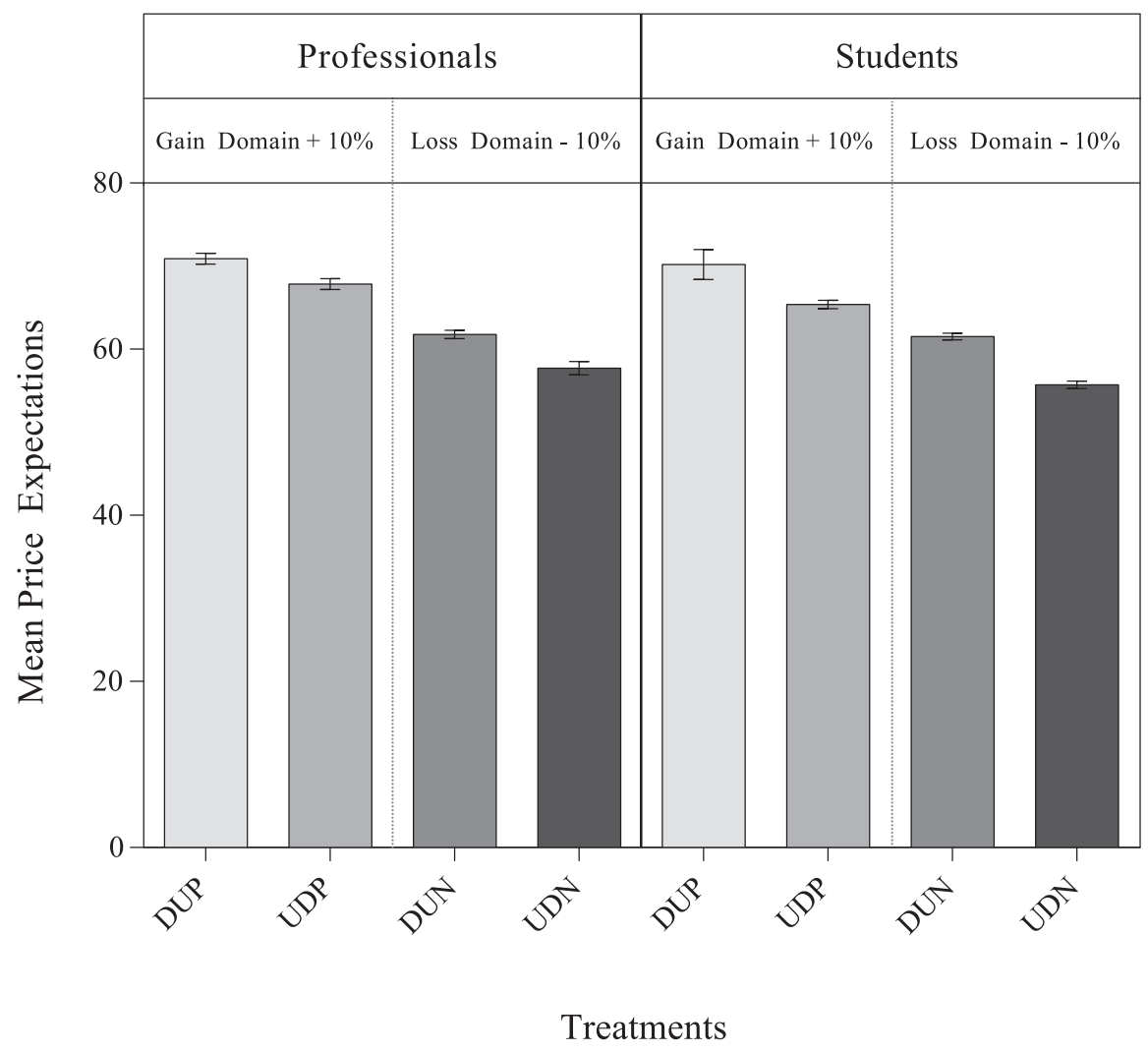

Fig. 2. Mean 12-month price expectations (starting price of 61 Euro) of professionals and students across treatments, separated into the gain and loss domains. Bars indicate whiskers of the standard error of the mean ( \pm SEM).

With regard to professionals, we find a significant mean price expectation difference between stocks with identical returns and different price paths in the gain domain (average of 3.07, 70.91 vs. 67.84; two-tailed $t$-test; $p=0.000, N=150$ ), and in the loss domain (average of $4.07,61.79$ vs. 57.71 ; two-tailed $t$-test; $p=0.000, N=150$ ). Henceforth, these differences are referred to as "expectation gaps". Similarly, we find significant expectation gaps in the gain domain (average of 4.80 , 70.20 vs. 65.40; two-tailed t-test; $p=0.000, N=576$ ) and in the loss domain (average of 5.82, 61.53 vs. 55.71; two-tailed $t$-test; $p=0.000, N=576$ ) among students.

For a closer inspection of the treatment effects and subject pool differences, we run multivariate OLS-regressions with price expectations as the dependent variable, controlled for heteroscedasticity. Furthermore, we test for autocorrelation and multicollinearity, which we can rule out. ${ }^{9}$ Following the suggestion in Benjamin et al. (2017), we lower the default $p$-value threshold for statistical significance to $0.5 \%$ in all econometric specifications, to reduce the likelihood of false positives and hence to improve the robustness of scientific findings. This leaves us with significance levels of $5 \%, 1 \%$, and $0.5 \%$. As outlined in Table 2, POS_RETURN indicates stocks with positive return while DOWN_UP is a binary dummy for all price paths showing a down-up price pattern. The variables DOWN_UP x PROF and POS_RETURN x PROF represent interaction terms between the variable PROF, indicating a binary dummy for professionals and the dummies DOWN_UP and POS_RETURN, respectively. Moreover, we include position dummies to control for potential order effects within the eight pre-defined path sequences.

We find that the coefficient of DOWN_UP is significantly positive, implying that down-up sequences of stock prices are associated with more optimistic one-year price expectations in both samples (see columns 1 and 3 in Table 2). This indicates that both professionals and students expect short-term trend continuation, which is in line with the results of Grosshans and Zeisberger (2018). Beliefs in short-term trend continuation may actually partly be reasonable with respect to investment performance due to empirically documented excess returns based on momentum trading strategies (Jegadeesh and Titman, 1993; 2001). In addition, professionals and students extrapolate past returns, which is indicated by the significantly positive coefficient of POS_RETURN in both subject pools. Landier et al. (2017) find that students systematically extrapolate

\footnotetext{
${ }^{9}$ Autocorrelation was tested by using the Durbin-Watson test, heteroscedasticity was inspected by using the White test and multicollinearity was tested by drawing on the variance inflation factor (VIF).
} 
Table 2

OLS-Regression with price expectations of professionals and students as the dependent variable. POS_RETURN indicates stocks with positive return while DOWN_UP is a binary dummy for all price paths showing a down-up price pattern. The variables DOWN_UP $\mathrm{x}$ PROF and POS_RETURN x PROF represent interaction terms between the variable PROF, indicating a binary dummy for professionals and the dummies DOWN_UP and POS_RETURN, respectively.

\begin{tabular}{|c|c|c|c|c|c|c|}
\hline & \multicolumn{2}{|c|}{ Professionals } & \multicolumn{2}{|c|}{ Students } & \multicolumn{2}{|c|}{ Joint } \\
\hline & Model (I) & Model (II) & Model (I) & Model (II) & Model (I) & Model (II) \\
\hline DOWN_UP & $\begin{array}{l}3.573^{* * *} \\
(0.821)\end{array}$ & $\begin{array}{l}2.560^{* * * *} \\
(0.840)\end{array}$ & $\begin{array}{l}5.310^{* * *} \\
(1.134)\end{array}$ & $\begin{array}{l}4.506^{* * *} \\
(1.459)\end{array}$ & $\begin{array}{l}4.951^{* * *} \\
(0.916)\end{array}$ & $\begin{array}{l}4.426^{* * *} \\
(1.384)\end{array}$ \\
\hline POS_RETURN & $\begin{array}{l}9.627^{* * *} \\
(0.548)\end{array}$ & $\begin{array}{l}6.795^{* * *} \\
(0.896)\end{array}$ & $\begin{array}{l}9.176^{* * * *} \\
(0.851)\end{array}$ & $\begin{array}{l}7.311^{* * * *} \\
(1.615)\end{array}$ & $\begin{array}{l}9.269^{* * *} \\
(0.684)\end{array}$ & $\begin{array}{l}7.124^{* * *} \\
(1.439)\end{array}$ \\
\hline SATISFACTION & & $\begin{array}{l}0.858^{* * *} \\
(0.215)\end{array}$ & & $\begin{array}{c}0.572^{*} \\
(0.288)\end{array}$ & & $\begin{array}{c}0.630^{* *} \\
(0.230)\end{array}$ \\
\hline MALE & & $\begin{array}{c}0.660 \\
(0.854)\end{array}$ & & $\begin{array}{c}0.057 \\
(1.944)\end{array}$ & & $\begin{array}{c}0.143 \\
(1.668)\end{array}$ \\
\hline DOWN_UP x PROF & & & & & & $\begin{array}{r}-1.587 \\
(1.384)\end{array}$ \\
\hline POS_RETURN x PROF & & & & & & $\begin{array}{c}0.413 \\
(1.085)\end{array}$ \\
\hline PROF & & & & & & $\begin{array}{c}1.973 \\
(1.017)\end{array}$ \\
\hline Constant & $\begin{array}{l}57.963^{* * *} \\
(0.733)\end{array}$ & $\begin{array}{l}60.222^{* * *} \\
(1.263)\end{array}$ & $\begin{array}{l}55.969^{* * *} \\
(0.585)\end{array}$ & $\begin{array}{l}57.912^{* * *} \\
(0.807)\end{array}$ & $\begin{array}{l}56.381^{* * *} \\
(0.489)\end{array}$ & $\begin{array}{l}58.035^{* * *} \\
(0.722)\end{array}$ \\
\hline Position Controls? & No & Yes & No & Yes & No & Yes \\
\hline Observations & 600 & 600 & 2304 & 2304 & 2904 & 2904 \\
\hline$R^{2}$ & 0.294 & 0.322 & 0.048 & 0.050 & 0.057 & 0.061 \\
\hline F-Statistic & 154.721 & 49.426 & 87.867 & 47.414 & 138.704 & 74.064 \\
\hline
\end{tabular}

${ }^{*} p<0.05,{ }^{* *} p<0.01,{ }^{* * *} p<0.005$ represent the $5 \%, 1 \%$, and $0.5 \%$ significance levels. Dependent variable: EXPECTATIONS. 150 professionals and 576 students generated 600 and 2304 observations in a within-subjects design (four price paths each). Clustered standard errors on a subject level are presented in parentheses (150 clusters for professionals and 576 clusters for students).

past realizations of a stochastic process into the future. Our findings regarding return extrapolation in both subject pools are in line with their results. Due to the significant correlation between price expectations and satisfaction levels in both subject pools (Spearman correlation coefficients: 0.50 in the professional sample; $p=0.000, N=150$, and 0.42 in the student sample; $p=0.000, N=576$ ), Models II in Table 2 control for satisfaction levels by including the corresponding variable SATISFACTION in order to isolate the direct effect on forward-looking expectations. In particular, we find that the effects of DOWN_UP and POS_RETURN remain robust.

Interestingly, the magnitudes of both effects (DOWN_UP and POS_RETURN) are fairly large in both subject pools. For instance, price paths that recovered from a trough lead to price expectations that are on average more than 2.5 Euro higher for professionals and 4.5 Euro higher for students compared to price paths with the inverse pattern (see columns 2 and 4 in Table 2). Nevertheless, even though the price expectations of professionals and students are markedly affected by stock price paths, columns 2 and 4 in Table 2 show that final returns exhibit a stronger impact on price expectations in both subject pools, whereby these differences are also highly significant according to post-estimation Wald tests (professionals: coefficient difference of $4.24,6.80$ vs. $2.56 ; p=0.000, N=150$; students: coefficient difference of $2.81,7.31$ vs. $4.51 ; p=$ $0.000, N=576$ ).

Finally, results of the joint regression (column 6 in Table 2) show that there is no significant difference in the influence of price paths and final returns on price expectations between professionals and students.

We hypothesize that a lack of cognitive reflection (i.e., lack of "system 2" thinking), which can be attributed to the dominance of the so-called "system 1" thinking (Epstein, 1994; Kahneman, 2013), might be a potential driver of absolute expectation gaps (i.e., price expectation differences between stocks with identical returns, but different price paths. Thus, absolute expectation gaps are defined as $|\mathrm{DU}-\mathrm{UD}|) .{ }^{10}$ Therefore, we expect to find a relationship between higher absolute expectation gaps and lower cognitive reflection. Absolute expectation gaps are in general significantly smaller for professionals than for students (magnitude of -2.83 Euro). ${ }^{11}$ Regarding the role of cognitive reflection, we find that professionals' CRT scores significantly explain the absolute expectation gaps. Specifically, absolute expectation gaps decrease by 1.9 Euro with every correct answer in the CRT (see column 1 of Table 3). Although the coefficient of CRT for students goes in the same direction, it is marginally insignificant. Furthermore, we do not find any gender effects with respect to the absolute expectation gaps.

\footnotetext{
10 DU stands for both stocks with a down-up path and UD stands for both stocks with an up-down path.

11 Due to the interaction term POS_RETURN x PROF, the coefficient of the variable PROF in column 3 of Table 3 indicates the difference in absolute expectation gaps between students and professionals in the loss domain. When we remove the interaction term from the regression, we obtain a coefficient of the variable PROF of $-2.83(p=0.004)$, which now indicates the difference over both domains.
} 
Table 3

OLS-regression on absolute expectation gaps across final returns, gender, CRT, and subject pools.

\begin{tabular}{lccc}
\hline & Professionals & Students & Joint \\
\hline POS_RETURN & -0.253 & 0.866 & 0.866 \\
MALE & $(0.659)$ & $(1.565)$ & $(1.565)$ \\
& -0.633 & -3.111 & -2.782 \\
CRT & $(2.309)$ & $(4.269)$ & $(3.657)$ \\
& $-1.899^{* * *}$ & -1.098 & $-1.228^{*}$ \\
POS_RETURN x PROF & $(0.582)$ & $(0.679)$ & $(0.547)$ \\
& & & -1.120 \\
PROF & & & $(1.697)$ \\
& & & $-2.271^{* *}$ \\
Constant & $12.596^{* * *}$ & $15.501^{* * *}$ & $(0.817)$ \\
& $(2.497)$ & $(4.539)$ & $15.484^{* * *}$ \\
Observations & 300 & 1152 & $(3.845)$ \\
$R^{2}$ & 0.054 & 0.004 & 1452 \\
F-Statistic & 3.633 & 1.577 & 0.006 \\
& & & 4.060 \\
\hline
\end{tabular}

${ }^{*} p<0.05,{ }^{* *} p<0.01,{ }^{* * *} p<0.005$ represent the $5 \%, 1 \%$, and $0.5 \%$ significance levels. Dependent variable: absolute expectation gaps: $|\mathrm{DU}-\mathrm{UD}|$, calculated as the absolute difference in expectations for price paths with equal final returns. Two observations for each subject enter the regression. Clustered standard errors on a subject level are presented in parentheses (150 clusters for professionals and 576 clusters for students).

\subsection{Investor satisfaction}

Turning to the results on investor satisfaction, Fig. 3 shows return-specific treatment differences in the self-reported mean satisfaction levels of professionals and students. Paired-sample $t$-test results of the treatments and subject pools are provided in Table A2 in the Appendix. In the professional sample, we find significant differences in satisfaction levels between both price paths in the gain domain (average of $0.94,1.99$ vs. 1.05 ; two-tailed $t$-test; $p=0.000, N=150$ ) and in the loss domain (average of $1.53,-0.92$ vs. -2.45 ; two-tailed $t$-test; $p=0.000, N=150$ ). These differences are henceforth referred to as "satisfaction gaps". In addition, students exhibit significant satisfaction gaps in both, the gain domain (average of 1.24, 2.24 vs. 1.00; two-tailed t-test; $p=0.000, N=576$ ) and the loss domain (average of 1.57, -0.85 vs. $-2.42 ;$ two-tailed t-test; $p=0.000, N=576)$, which is in line with Grosshans and Zeisberger (2018). This implies that both subject pools are

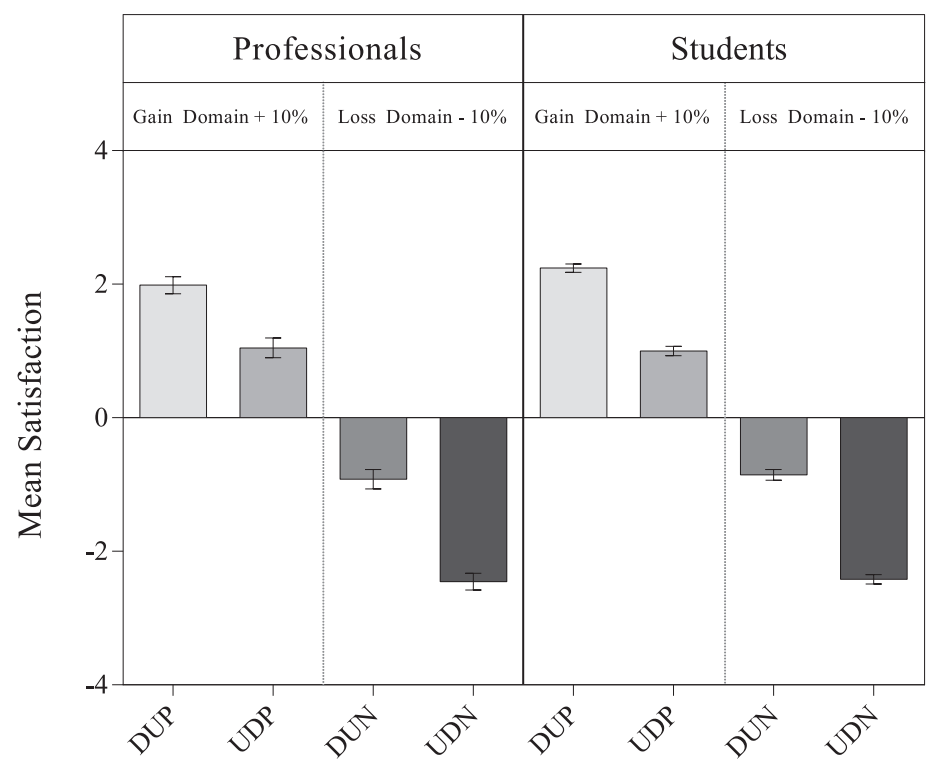

Treatments

Fig. 3. Mean self-reported satisfaction levels of professionals and students across treatments, separated into gain and loss domains. Satisfaction levels range from -4 to 4 , where 0 indicates neutrality. Bars indicate whiskers of the standard error of the mean $( \pm$ SEM). 
Table 4

Ordered logistic-regression with satisfaction levels of professionals and students as the dependent variable. POS_RETURN indicates stocks with positive return while DOWN_UP is a binary dummy for all price paths showing a down-up price pattern. The variables DOWN_UP x PROF and POS_RETURN x PROF represent interaction terms between the variable PROF, indicating a binary dummy for professionals and the dummies DOWN_UP and POS_RETURN, respectively.

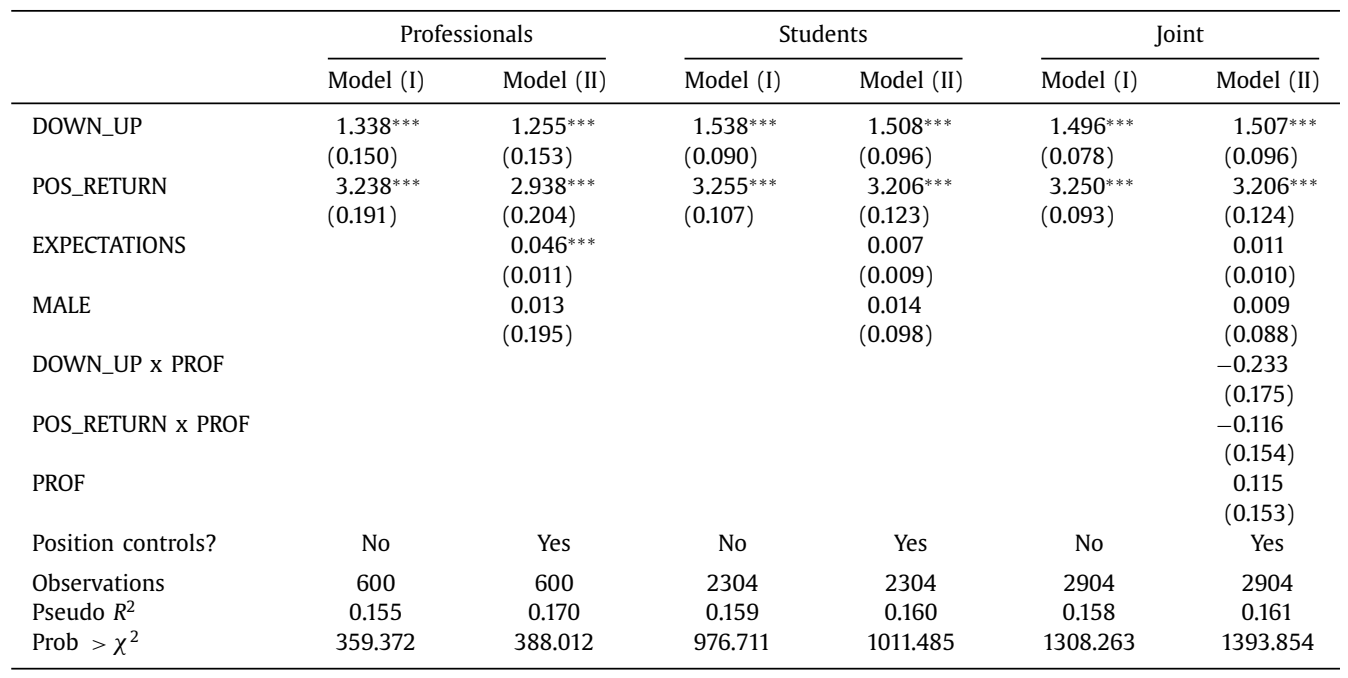

${ }^{*} p<0.05,{ }^{* *} p<0.01,{ }^{* * *} p<0.005$ represent the $5 \%, 1 \%$, and $0.5 \%$ significance levels. Dependent variable: SATISFACTION. 150 professionals and 576 students generated 600 and 2304 observations in a within-subjects design (four price paths each). Clustered standard errors on a subject level are presented in parentheses (150 clusters for professionals and 576 clusters for students).

significantly more satisfied with stocks that first decrease in price and then recover compared to stocks with the inverse price pattern, when the final return is held constant.

In Table 4, we deepen our analyses and report ordered logistic-regression results with self-reported satisfaction levels as the dependent variable. We find that stocks that first decrease and then recover in price yield significantly higher selfreported satisfaction levels compared to stocks with the opposite pattern, which confirms our $t$-test results. This finding holds for both subject pools and the effects are strong in magnitude (coefficients of DOWN_UP range between 1.34 and 1.54 in columns 1 and 3, respectively). Similarly, stock price paths with positive returns lead to significantly higher satisfaction levels compared to those with negative returns for both professionals and students. Models II also control for price expectations (EXPECTATIONS) to isolate the effect of the pathway and the return on satisfaction with past stock performance that is not driven through the channel of expectations. Models II show that the effects of DOWN_UP and POS_RETURN on satisfaction levels remain robust. Importantly, the effect sizes of the influence of final returns on investor satisfaction are larger among both pools compared to the effect sizes of the price paths, which can be seen in columns 2 and 4 in Table 4. According to post-estimation Wald tests, these differences are highly significant (professionals: coefficient difference of $1.68,2.94$ vs. $1.26, p=0.000, N=150$; students: coefficient difference of $1.70,3.21$ vs. $1.51, p=0.000$, $N=576$ ). Interestingly, the ratio between the effect sizes of DOWN_UP and POS_RETURN is nearly identical in both subject pools.

When analyzing the coefficients in the joint regression in columns 5 and 6 of Table 4, we find that there is no significant difference between the subject pools regarding the influence of the price path and the return on satisfaction levels.

The presented results on satisfaction levels raise a question about the source of the frame-dependent differences in satisfaction across treatments. To investigate possible explanatory individual characteristics, we utilize the absolute satisfaction gaps $|\mathrm{DU}-\mathrm{UD}|$ over both the gain and the loss domains as the dependent variable in an ordered logistic-regression model.

Again, we hypothesize that a lack of cognitive reflection might be a potential driver of the absolute satisfaction gaps (i.e., satisfaction level differences between stocks with identical returns but different price paths-absolute satisfaction gaps are defined as $|\mathrm{DU}-\mathrm{UD}|)$. If subjects would have evaluated the stocks analytically, they would have noticed that the only economically relevant variable driving their utility-the final return-is equivalent for treatments UDN and DUN as well as for UDP and DUP, respectively. The regression results are shown in Table 5. In contrast to the results for price expectations, we find no significant difference in absolute satisfaction gaps between professionals and students. ${ }^{12}$ Turning to the role of cognitive reflection, we report that the CRT results significantly explain absolute satisfaction gaps. Specifically, the satisfaction gaps decrease by 0.37 (professionals) and 0.11 (students) with every correct answer in the CRT (see columns 1 and

\footnotetext{
12 Because of the interaction term POS_RETURN x PROF, the coefficient of PROF in column 3 of Table 5 indicates the difference in absolute satisfaction gaps between professionals and students in the loss domain. When we remove the interaction term from the regression, the coefficient of PROF remains non-significant (coefficient of $-0.163, p=0.208$ ), now measuring the difference over both domains.
} 
Table 5

Ordered logistic-regression on absolute satisfaction gaps across final returns, gender, CRT, and subject pools.

\begin{tabular}{lccc}
\hline & Professionals & Students & Joint \\
\hline POS_RETURN & -0.060 & $-0.240^{* *}$ & $-0.234^{* *}$ \\
& $(0.199)$ & $(0.089)$ & $(0.088)$ \\
MALE & -0.433 & -0.135 & -0.185 \\
& $(0.365)$ & $(0.141)$ & $(0.132)$ \\
CRT & $-0.367^{* * *}$ & $-0.113^{*}$ & $-0.161^{* * *}$ \\
& $(0.127)$ & $(0.057)$ & $(0.052)$ \\
POS_RETURN x PROF & & & 0.167 \\
& & & $(0.226)$ \\
PROF & & & -0.246 \\
& & & $(0.169)$ \\
Observations & 300 & 1152 & 1452 \\
Pseudo $R^{2}$ & 0.015 & 0.003 & 0.005 \\
Prob $>\chi^{2}$ & 11.367 & 13.607 & 24.575 \\
\hline
\end{tabular}

${ }^{*} p<0.05,{ }^{* *} p<0.01,{ }^{* * *} p<0.005$ represent the $5 \%, 1 \%$, and $0.5 \%$ significance levels. Clustered standard errors on a subject level are presented in parentheses. Dependent variable: absolute satisfaction gaps: $|D U-U D|$, calculated as the absolute difference in satisfaction for price paths with equal final returns. Two observations for each subject enter the regression. Clustered standard errors on a subject level are presented in parentheses (150 clusters for professionals and 576 clusters for students).

2 of Table 3). Nevertheless, although the level of cognitive reflection reduces absolute satisfaction gaps, professionals and students still exhibit strong frame-dependent preferences, which influence their investment satisfaction. Moreover, we find no gender effects with respect to absolute satisfaction gaps in both subject pools.

\subsection{Other results}

Turning to the other elicited variables, we find internally consistent results. Recommendations about selling the stocks on a 4-point Likert scale are significantly correlated with price expectations (Spearman correlation coefficients: 0.38 in the professional sample; $p=0.000, N=150$; and 0.43 in the student sample; $p=0.000, N=576$ ) and with satisfaction levels (Spearman correlation coefficients: 0.18 in the professional sample; $p=0.000, N=150$; and 0.20 in the student sample; $p=0.000, N=576)$.

Moreover, in Tables A4 and A5 we run our main regressions with the neutral selling prices and the $95 \%$ confidence bounds of price estimates for the upcoming 12 months as dependent variables, respectively (for the latter variable we truncated the data set and excluded the $2.5 \%$ of the widest and narrowest bounds to control for outliers).

Importantly, we report that professionals assign a significantly higher neutral selling price to stocks with positive returns compared to those with negative returns and that price expectations are significantly positively associated with neutral selling prices. In line with Baucells et al. (2011), we find that neutral selling prices are lower for price paths with a downup pattern compared to the reversed pattern for both subject pools. Following Chen and Rao (2002) and Baucells et al. (2011), this finding can be interpreted by adjusted reference points conditional on the price development-i.e., an initial downturn in prices yields lower reference points (prices) compared to an initial price increase. Additionally, we find no clear pattern regarding the $95 \%$ confidence bounds of price estimates, except that professionals come up with significantly wider intervals. A possible explanation for this might be that financial professionals are aware of the difficulty to make an exact point prediction of a future market price and, thus, they might hedge themselves by applying wider confidence intervals. Two other explanations, put forward by Grosshans and Zeisberger (2018), originate in the link between expectations and the width of the confidence intervals, which we also find in our sample of professionals (see Table A5). Professionals might choose wider confidence intervals in order to hedge their optimistic forecasts or because they expect higher returns to come at the cost of higher volatility.

\section{Conclusion}

In this paper we investigated the impact of varying levels of investment returns and different price paths on the price expectations and the satisfaction levels of financial professionals and students. In total, we conducted experiments with 150 professionals and 576 students, systematically varying price paths according to the final return (positive or negative) and the way in which the final return is achieved (upswing followed by downswing or vice versa). We found that professionals and students showed the most optimistic price expectations and were most satisfied if assets fell in price first and recovered afterwards. In addition, price expectations and satisfaction levels of professionals and students were highest after positive returns. Finally, we concluded that both professionals and students reacted in a qualitatively similar way across the treatments. Nevertheless, with respect to absolute expectation gaps, professionals showed more consistent and less frame-dependent behavior. In particular, professionals' absolute expectation gaps were significantly smaller compared to those of students, indicating that their price expectations are less driven by the frame of the price path. 
Our findings raise the question why we observe similar behavior between student subjects and highly sophisticated professionals who gained a lot of experience in their job. We find that such a level of experience does not prevent professionals from being prone to framing effects. As mentioned in the introductory section, the literature on the behavior of financial professionals is small, but growing at a higher pace, hopefully leaving us with a meaningful picture about professionals' behavioral biases and their differences to non-professionals in a couple of years (e.g., Abdellaoui et al., 2013; Cipriani and Guarino, 2009; Cohn et al., 2014; 2017; Haigh and List, 2005; Kirchler et al., 2018b; List, 2004). Hence, at this point it would be speculative to answer why professionals are similarly influenced by framing effects as students. As already shown in some of the papers cited above, professionals often do not act more rational compared to students regarding several cognitive biases. Some of these cognitive biases, like the framing effect, might be hardwired into our brain, making it very difficult to overcome them, also for sophisticated individuals.

The results of our study have far-reaching implications for real-world decision-making. The fact that professionals are influenced by past returns of the stocks and by the way (the frame) in which these returns were achieved, has important consequences for their price expectations on stock markets. It seems that professionals (and to a moderately stronger degree students) show beliefs in short-term trend continuation, which is supported by empirical data (e.g., Greenwood and Shleifer, 2014) and also applied in heterogeneous agent models (see, e.g., Hommes, 2006; Hommes and in 't Veld, 2017). Our findings are specifically relevant given the importance of professionals' beliefs about future developments of the stock market in general and about individual stocks in particular. In the finance industry, one of the key competences of analysts, traders, and fund managers should be the ability to predict future developments better than others. If, as outlined by our study, their expectations are systematically influenced by trivial frames such as price patterns, it might be necessary to think about ways to de-bias professionals in order to reduce their proneness to framing effects. Irrespective of the profitability of such strategies for individual investors, from an overall societal perspective it is sub-optimal if investors base their expectations on past price patterns and exhibit trend following behavior, since such a behavior has been shown to trigger or reinforce price bubbles (Hommes et al., 2008; Hommes and in 't Veld, 2017). Moreover, one direction for future research would be to have professionals imagine that they are administering financial products not for themselves but rather for their clients. Such a setting has been shown to mitigate framing effects for students, which is explained by lower levels of emotional involvement, leading to more objectivity (Ziegler and Tunney, 2015). 


\section{Appendix A}

\section{A1. Additional figures and tables}

Table A1

Pairwise treatment differences in price expectations of professionals, utilizing paired sample t-tests. (results of the student sample are shown in parentheses.)

\begin{tabular}{|c|c|c|c|c|c|}
\hline \multicolumn{6}{|c|}{ Pairwise price expectation differences between treatments } \\
\hline Treatments & Obs & & & Std. err. & $\operatorname{pr}(T>t)$ \\
\hline DUP - UDN & $150(576)$ & $13.20^{* * *}$ & $(14.49 * * *)$ & $1.11(1.90)$ & $0.000(0.000)$ \\
\hline DUP - DUN & $150(576)$ & $9.12^{* * *}$ & $\left(8.66^{* * *}\right)$ & $0.68(1.56)$ & $0.000(0.000)$ \\
\hline UDP - UDN & $150(576)$ & $10.12^{* * *}$ & $\left(9.69^{* * *}\right)$ & $0.73(0.56)$ & $0.000(0.000)$ \\
\hline UDP - DUN & $150(576)$ & $6.01^{* * *}$ & $\left(3.87^{* * *}\right)$ & $0.82(0.64)$ & $0.000(0.000)$ \\
\hline \multicolumn{6}{|c|}{ Absolute expectation gaps } \\
\hline Treatments & Obs & \multicolumn{2}{|c|}{ Difference } & Std. err. & $\operatorname{pr}(T>t)$ \\
\hline DUP - UDP & $150(576)$ & $3.07^{* * *}$ & $\left(4.80^{* * *}\right)$ & $0.93(1.86)$ & $0.000(0.000)$ \\
\hline DUN - UDN & $150(576)$ & $4.07^{* * *}$ & $\left(5.82^{* * *}\right)$ & $0.94(0.63)$ & $0.000(0.000)$ \\
\hline
\end{tabular}

Note: ${ }^{*} p<0.05,{ }^{* *} p<0.01,{ }^{* * *} p<0.005$ represent the $5 \%, 1 \%$, and $0.5 \%$ significance levels.

Table A2

Pairwise treatment differences in satisfaction levels of professionals, utilizing paired sample t-tests (results of the student sample are shown in parentheses.)

\begin{tabular}{|c|c|c|c|c|c|}
\hline \multicolumn{6}{|c|}{ Pairwise satisfaction differences between treatments } \\
\hline Treatments & Obs & \multicolumn{2}{|c|}{ Difference } & Std. err. & $\operatorname{pr}(T>t)$ \\
\hline DUP - UDN & $150(576)$ & $4.44^{* * *}$ & $\left(4.66^{* * *}\right)$ & $0.17(0.10)$ & $0.000(0.000)$ \\
\hline DUP - DUN & $150(576)$ & $2.91^{* * *}$ & $\left(3.10^{* * *}\right)$ & $0.17(0.09)$ & $0.000(0.000)$ \\
\hline UDP - UDN & $150(576)$ & $3.50 * * *$ & $\left(3.42^{* * *}\right)$ & $0.17(0.09)$ & $0.000(0.000)$ \\
\hline UDP - DUN & $150(576)$ & $1.97^{* * *}$ & $\left(1.85^{* * *}\right)$ & $0.22(0.11)$ & $0.000(0.000)$ \\
\hline \multicolumn{6}{|c|}{ Satisfaction gaps } \\
\hline Treatments & Obs & \multicolumn{2}{|c|}{ Difference } & Std. err. & $\operatorname{pr}(T>t)$ \\
\hline DUP - UDP & $150(576)$ & $0.94^{* * *}$ & $\left(1.24^{* * *}\right)$ & $0.19(0.09)$ & $0.000(0.000)$ \\
\hline DUN - UDN & $150(576)$ & $1.53^{* * *}$ & $\left(1.57^{* * *}\right)$ & $0.17(0.09)$ & $0.000(0.000)$ \\
\hline
\end{tabular}

Note: ${ }^{*} p<0.05,{ }^{* *} p<0.01,{ }^{* * *} p<0.005$ represent the $5 \%, 1 \%$, and $0.5 \%$ significance levels.

Table A3

Shares of self-stated job functions of financial professionals and self-reported shares of asset classes with which the professionals primarily work with.

\begin{tabular}{lc}
\hline Job functions & $\%$ of total $(N=144)$ \\
\hline Chief-level executives & $2.10 \%$ \\
Consultants/financial advisors & $26.38 \%$ \\
Fund managers/traders & $15.97 \%$ \\
Investment/portfolio managers & $25.00 \%$ \\
Research analysts & $6.25 \%$ \\
Other & $24.30 \%$ \\
Main asset class & \\
Derivatives & $9.04 \%$ \\
Equity & $34.72 \%$ \\
Fixed-income & $22.22 \%$ \\
Multi-asset & $20.83 \%$ \\
Other & $13.19 \%$ \\
\hline
\end{tabular}

Note: Six financial professionals did not state any specific job functions, leaving us with information of 144 financial professionals. 
Table A4

OLS-Regression with NEUTRAL_SELLING_PRICE of professionals and students as dependent variable. POS_RETURN indicates stocks with positive return while DOWN_UP is a binary dummy for all price paths showing a down-up price pattern. The variables DOWN_UP $\mathrm{x}$ PROF and POS_RETURN $\mathrm{x}$ PROF represent interaction terms between the variable PROF, indicating a binary dummy for professionals, and the dummies DOWN_UP and POS_RETURN, respectively.

\begin{tabular}{|c|c|c|c|c|c|c|}
\hline & \multicolumn{2}{|c|}{ Professionals } & \multicolumn{2}{|c|}{ Students } & \multicolumn{2}{|c|}{ Joint } \\
\hline & Model (I) & Model (II) & Model (I) & Model (II) & Model (I) & Model (II) \\
\hline DOWN_UP & $\begin{array}{c}-2.145^{* * *} \\
(0.397)\end{array}$ & $\begin{array}{c}-2.144^{* * *} \\
(0.398)\end{array}$ & $\begin{array}{c}-3.882^{* * *} \\
(0.348)\end{array}$ & $\begin{array}{c}-3.882^{* * *} \\
(0.347)\end{array}$ & $\begin{array}{c}-3.705^{* * *} \\
(0.308)\end{array}$ & $\begin{array}{c}-3.836^{* * *} \\
(0.353)\end{array}$ \\
\hline EXPECTATIONS & $\begin{array}{c}0.119^{* * * *} \\
(0.031)\end{array}$ & $\begin{array}{c}0.121^{* * *} \\
(0.031)\end{array}$ & $\begin{array}{l}0.425^{* * *} \\
(0.031)\end{array}$ & $\begin{array}{c}0.425^{* * * *} \\
(0.031)\end{array}$ & $\begin{array}{c}0.416^{* * *} \\
(0.036)\end{array}$ & $\begin{array}{c}0.417^{* * *} \\
(0.036)\end{array}$ \\
\hline POS_RETURN & $\begin{array}{l}1.989^{* * *} \\
(0.413)\end{array}$ & $\begin{array}{l}1.921^{* * *} \\
(0.413)\end{array}$ & $\begin{array}{c}-0.474 \\
(0.401)\end{array}$ & $\begin{array}{r}-0.475 \\
(0.396)\end{array}$ & $\begin{array}{c}-0.493 \\
(0.403)\end{array}$ & $\begin{array}{r}-0.396 \\
(0.424)\end{array}$ \\
\hline MALE & & $\begin{array}{r}-0.189 \\
(0.745)\end{array}$ & & $\begin{array}{r}-0.186 \\
(0.567)\end{array}$ & & $\begin{array}{c}-0.213 \\
(0.497)\end{array}$ \\
\hline DOWN_UP x PROF & & & & & & $\begin{array}{c}0.632 \\
(0.543)\end{array}$ \\
\hline POS_RETURN x PROF & & & & & & $\begin{array}{r}-0.541 \\
(0.439)\end{array}$ \\
\hline PROF & & & & & & $\begin{array}{c}0.141 \\
(0.541)\end{array}$ \\
\hline Constant & $\begin{array}{l}55.917^{* * *} \\
(1.767)\end{array}$ & $\begin{array}{l}55.582^{* * *} \\
(2.031)\end{array}$ & $\begin{array}{l}38.079 * * * \\
(1.806)\end{array}$ & $\begin{array}{l}37.303^{* * * *} \\
(1.971)\end{array}$ & $\begin{array}{l}38.595^{* * *} \\
(2.084)\end{array}$ & $\begin{array}{l}37.853^{* * *} \\
(2.197)\end{array}$ \\
\hline Position controls? & No & Yes & No & Yes & No & Yes \\
\hline Observations & 600 & 600 & 2304 & 2304 & 2904 & 2904 \\
\hline$R^{2}$ & 0.154 & 0.160 & 0.637 & 0.641 & 0.609 & 0.613 \\
\hline F-statistic & 35.506 & 17.041 & 148.354 & 72.439 & 158.545 & 55.074 \\
\hline
\end{tabular}

${ }^{*} p<0.05,{ }^{* *} p<0.01,{ }^{* * *} p<0.005$ represent the $5 \%, 1 \%$, and $0.5 \%$ significance levels. Dependent variable: NEUTRAL_SELLING_PRICE. 150 professionals and 576 students generated 600 and 2304 observations in a within-subjects design (four price paths each). Clustered standard errors on a subject level are presented in parentheses (150 clusters for professionals and 576 clusters for students).

\section{Table A5}

OLS-Regression with the width of the confidence interval (UPPER_BOUND - LOWER_BOUND) of professionals and students as dependent variable. POS_RETURN indicates stocks with positive return while DOWN_UP is a binary dummy for all price paths showing a down-up price pattern. The variables DOWN_UP x PROF and POS_RETURN x PROF represent interaction terms between the variable PROF, indicating a binary dummy for professionals, and the dummies DOWN_UP and POS_RETURN, respectively.

\begin{tabular}{|c|c|c|c|c|c|c|}
\hline & \multicolumn{2}{|c|}{ Professionals } & \multicolumn{2}{|c|}{ Students } & \multicolumn{2}{|c|}{ Joint } \\
\hline & Model (I) & Model (II) & Model (I) & Model (II) & Model (I) & Model (II) \\
\hline DOWN_UP & $\begin{array}{r}-0.838 \\
(0.842)\end{array}$ & $\begin{array}{r}-0.770 \\
(0.840)\end{array}$ & $\begin{array}{c}-0.735 \\
(0.454)\end{array}$ & $\begin{array}{r}-0.725 \\
(0.455)\end{array}$ & $\begin{array}{r}-0.651 \\
(0.399)\end{array}$ & $\begin{array}{c}-0.757 \\
(0.454)\end{array}$ \\
\hline POS_RETURN & $\begin{array}{c}0.327 \\
(1.219)\end{array}$ & $\begin{array}{c}0.254 \\
(1.223)\end{array}$ & $\begin{array}{c}0.423 \\
(0.489)\end{array}$ & $\begin{array}{c}0.421 \\
(0.478)\end{array}$ & $\begin{array}{c}0.726 \\
(0.453)\end{array}$ & $\begin{array}{c}0.366 \\
(0.486)\end{array}$ \\
\hline EXPECTATIONS & $\begin{array}{c}0.220^{*} \\
(0.098)\end{array}$ & $\begin{array}{c}0.215^{*} \\
(0.097)\end{array}$ & $\begin{array}{c}0.010 \\
(0.017)\end{array}$ & $\begin{array}{c}0.010 \\
(0.016)\end{array}$ & $\begin{array}{c}0.021 \\
(0.024)\end{array}$ & $\begin{array}{c}0.017 \\
(0.019)\end{array}$ \\
\hline MALE & & $\begin{array}{c}3.639 \\
(3.925)\end{array}$ & & $\begin{array}{c}2.025 \\
(1.302)\end{array}$ & & $\begin{array}{c}2.287 \\
(1.252)\end{array}$ \\
\hline DOWN_UP x PROF & & & & & & $\begin{array}{c}0.730 \\
(0.933)\end{array}$ \\
\hline POS_RETURN x PROF & & & & & & $\begin{array}{c}1.810 \\
(0.965)\end{array}$ \\
\hline PROF & & & & & & $\begin{array}{c}4.335^{* * *} \\
(1.495)\end{array}$ \\
\hline Constant & $\begin{array}{l}24.391^{* * *} \\
(5.946)\end{array}$ & $\begin{array}{c}21.617^{* *} \\
(7.664)\end{array}$ & $\begin{array}{l}31.982^{* * *} \\
(1.236)\end{array}$ & $\begin{array}{l}32.423^{* * *} \\
(1.653)\end{array}$ & $\begin{array}{l}32.330^{* * *} \\
(1.587)\end{array}$ & $\begin{array}{l}31.497^{* * *} \\
(1.769)\end{array}$ \\
\hline Position controls? & No & Yes & No & Yes & No & Yes \\
\hline Observations & 582 & 582 & 2195 & 2195 & 2777 & 2777 \\
\hline$R^{2}$ & 0.014 & 0.021 & 0.001 & 0.008 & 0.002 & 0.027 \\
\hline F-statistic & 4.288 & 2.682 & 1.598 & 3.383 & 2.934 & 4.938 \\
\hline
\end{tabular}

${ }^{*} p<0.05,{ }^{* *} p<0.01,{ }^{* * *} p<0.005$ represent the $5 \%, 1 \%$, and $0.5 \%$ significance levels. Clustered standard errors on a subject level are presented in parentheses. Dependent variable: width of confidence interval (UPPER_BOUND_LOWER_BOUND). 150 professionals and 576 students generated 600 and 2304 observations in a within-subjects design (four price paths each). Due to outliers, the top and bottom $2.5 \%$ of all observations were dropped. 


\section{A2. Experimental instructions}

All instructions in this experiment have been provided through self-explaining screens in z-Tree. The experimental protocol was identical for the professional and the student sample.

\section{Dear Participant!}

In the following you will be presented with four stock price developments. Please imagine for each case that you have bought the respective stock one year ago for your own portfolio and now observe its performance.

The presented performances are not related to the current real world market situation. Furthermore, the performances of all presented stocks are independent of each other.

Please take your time on each stock, imagine this was your own stock which you bought one year ago and ask yourself how you would feel when observing the respective performance.

Overall, this study will take you 5 - 6 minutes.

Fig. A1. Table. 


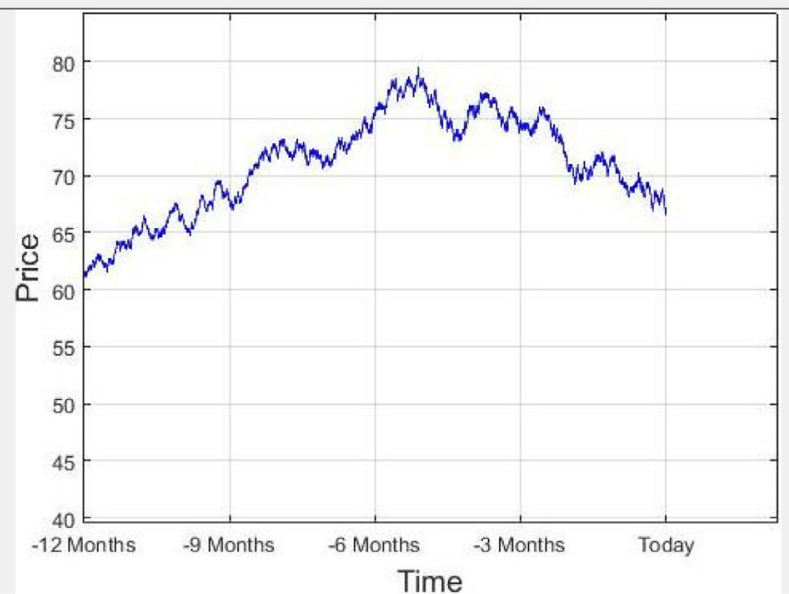

Please state your satisfaction with the stock on a scale ranging from -4 to 4 , where -4 indicates very unsatisfied and 4 indicates very satisfied.

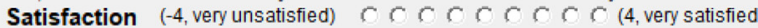

Please state your opinion on whether to hold or sell the stock, where 0 indicates very likely sell and 3 indicates very likely hold

Recommendation ( 0 , very likely sell) $\sim \subset \subset \subset(3$, very likely hold $)$

At what price would you feel neutral about selling your stock, i.e., be neither satisfied nor unsatisfied about the sale?

What is your estimate of the most likely stock price in 12 months?

What is your pessimistic estimate for the stock price in 12 months? (In $95 \%$ of the cases the price of the stock will be above this price.)

What is your optimistic estimate for the stock price in 12 months? (In $95 \%$ of the cases the price of the stock will be below this price.)

Fig. A1. Continued 


\begin{tabular}{|l|l|l|}
\hline Period 1 out of 1 & Remaining time [sec]: 79
\end{tabular}

In the following you will see 3 questions with different levels of difficulty. Answer as many as possible.

An IT-company offers you storage space. Every day your volume of data doubles. If it would need 20 days to max out the provided space, how long would it take to max out half of the space?

Days

A football shoe and a ball cost 110 Euro together. The shoe costs 70 Euro more than the ball. How much costs the ball?

Euro

5 machines need 5 minutes to produce 5 keyboards. How long would 80 machines need for 80 keyboards?

Minutes

How many of the above 3 questions do you think you have answered correctly?

Quantity (from 0 to 3 )

Fig. A1. Continued 
A3. Pictures of the experimental laboratories
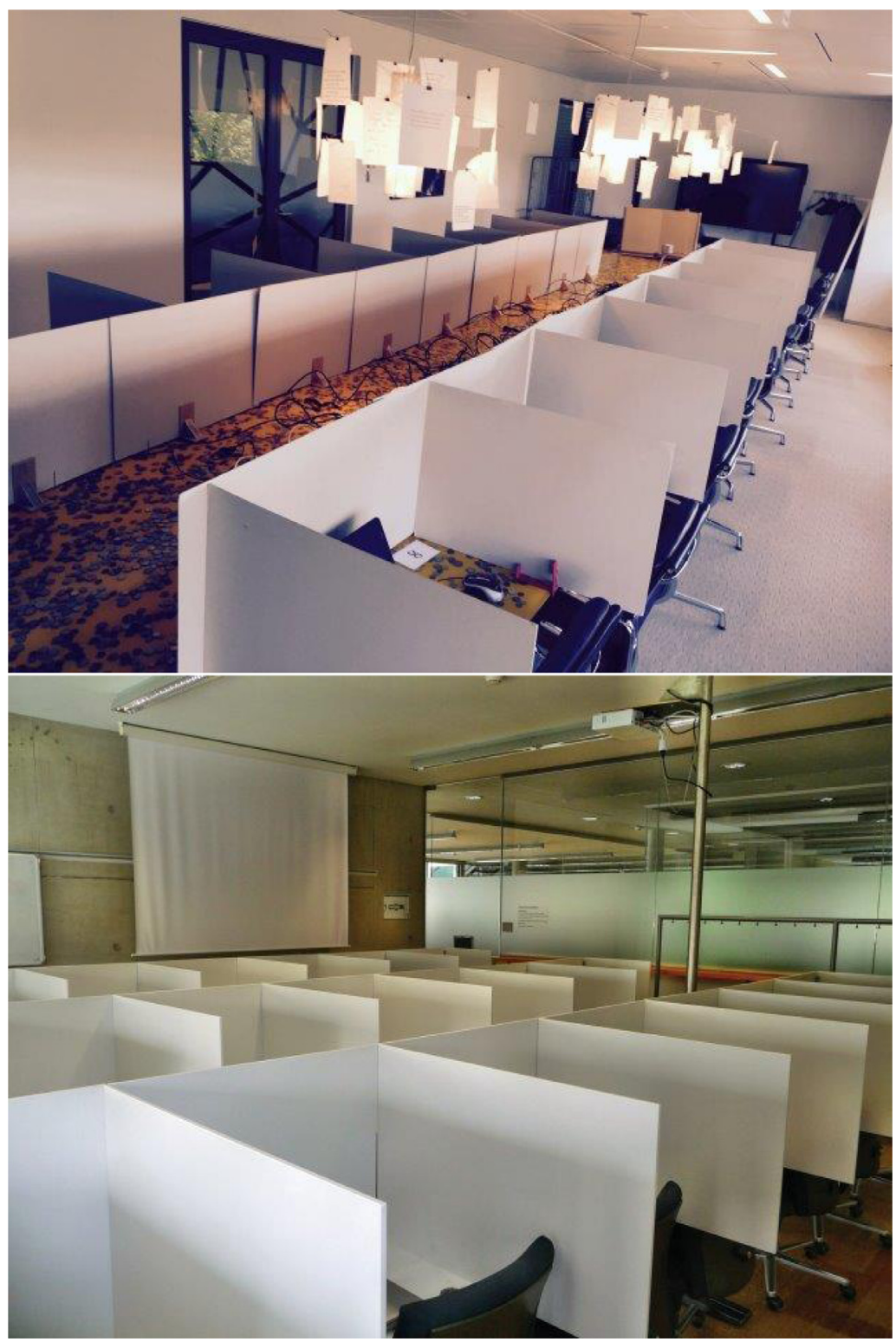

Fig. A2. Mobile laboratory and Innsbruck EconLab. Top: example of the mobile laboratory in the conference room of a financial institution. Bottom: Innsbruck EconLab. 


\section{References}

Abdellaoui, M., Bleichrodt, H., Kammoun, H., 2013. Do financial professionals behave according to prospect theory? An experimental study. Theory Dec. 74 (3), 411-429.

Alevy, J.E., Haigh, M.S., List, J.A., 2007. Information cascades: evidence from a field experiment with financial market professionals. J. Finance 62 (1), 151-180. Alexander, J.C., Ang, J.S., 1998. Do equity markets respond to earnings paths? Financ. Anal. J. 54 (4), 81-94.

Arrow, K.J., 1982. Risk perception in psychology and economics. Econ. Inquiry 20 (1), 1-9.

Baucells, M., Weber, M., Welfens, F., 2011. Close encounters of two kinds: False alarms and dashed hopes. Manag. Sci. 57 (3), $506-519$.

Benartzi, S., Thaler, R.H., 1999. Heuristics and biases in retirement savings behavior. J. Econ. Perspect. 45 (3), $364-381$.

Benjamin, D.J., Berger, J.O., Johannesson, M., Nosek, B.A., Wagenmakers, E.-J., Berk, R., Bollen, K.A., Brembs, B., Brown, L., et al., 2017. Redefine statistical significance. Nat. Hum. Behav. 2, 6-10.

Bergus, G., Gretchen, B., Barcey, T., John, W., Oppliger, R., 1998. Clinical diagnosis and the order of information. Med. Dec. Mak. 18 (4), $412-417$.

Blanchard, T.C., Wolfe, L.S., Vlaev, I., Winston, J.S., Hayden, B.Y., 2014. Biases in preferences for sequences of outcomes in monkeys. Cognition 130, 289-299.

Bosman, R., Kräussl, R., Mirgorodskaya, E., 2015. The "tone effect" of news on investor beliefs: an experimental approach. In: CFS Working Paper Series, 522. Goethe University, Center for Financial Studies (CFS), Frankfurt a.M.

Chapman, G.B., 1996. Expectations and preferences for sequences of health and money. Org. Behav. Hum. Dec. Process 67 (1), $59-75$.

Chen, A.H., Rao, A.R., 2002. Close encounters of two kinds: false alarms and dashed hopes. Market. Sci. 21 (2), $178-196$.

Cherian, J.A., Jarrow, R.A., 1998. Options markets, self-fulfilling prophecies, and implied volatilities. Rev. Deriv. Res. 2 (1), 5 -37.

Choi, J.J., Laibson, D., Madrian, B.C., 2010. Why does the law of one price fail? an experiment on index mutual funds. Rev. Financ. Stud. 23(4), 1405-1432.

Cipriani, M., Guarino, A., 2009. Herd behavior in financial markets: an experiment with financial market professionals. J. Eur. Econ. Assoc. 7 (1), $206-233$.

Cohn, A., Engelmann, J., Fehr, E., Maréchal, M., 2015. Evidence for countercyclical risk aversion: an experiment with financial professionals. Am. Econ. Rev. 105 (2), 860-885

Cohn, A., Fehr, E., Maréchal, M.A., 2014. Business culture and dishonesty in the banking industry. Nature 516, 86-89.

Cohn, A., Fehr, E., Maréchal, M.A., 2017. Do professional norms in the banking industry favor risk-taking? Rev. Financ. Stud. 30 (11), $3801-3823$.

Corgnet, B., DeSantis, M., Porter, D., 2018. What makes a good trader? on the role of intuition and reflection on trader performance. J. Finance 73 (3), $1113-1137$.

Deaves, R., Lüders, E., Schröder, M., 2010. The dynamics of overconfidence: evidence from stock market forecasters. J. Econ. Behav. Org. 75, 793-808.

Dreber, A., Ellingson, T., Johannesson, M., Rand, D.G., 2013. Do people care about social context? framing effects in dictator games. Exp. Econ. 16 (3), 349-371.

Druckman, J.N., 2001. Evaluating framing effects. J. Econ. Psychol. 22, 91-101.

Epstein, S., 1994. Integration of the cognitive and the psychodynamic unconscious. Am. Psychol. 49 (8), $709-724$.

Ferraro, F., Pfeffer, J., Sutton, R.I., 2005. Economics language and assumptions: how theories can become self-fulfilling. Acad. Manag. Rev. 30, 8-24.

Fischbacher, U., 2007. z-tree: Zurich toolbox for ready-made economic experiments. Exp. Econ. 10 (2), $171-178$.

Frederick, S., 2005. Cognitive reflection and decision making. J. Econ. Perspect. 19 (4), 25-42.

Gächter, S., Orzen, H., Renner, E., Starmer, C., 2009. Are experimental economists prone to framing effects? A natural field experiment. Scand. J. Econ. 70

(3), 443-446.

Greenwood, R., Shleifer, A., 2014. Expectations of returns and expected returns. Rev. Financ. Stud. 27 (3), $714-746$.

Grosshans, D., Zeisberger, S., 2018. All' s well that ends well? on the importance of how returns are achieved. J. Bank. Finance 87, 397-410.

Haigh, M.S., List, J.A., 2005. Do professional traders exhibit myopic loss aversion? An experimental analysis. J. Finance 60 (1), $523-534$.

Haugtvedt, C.P., Wegener, D.T., 1994. Message order effects in persuasion: an attitude strength perspective. J. Consum. Res. 21 (1), 205-218.

Hommes, C., 2006. Heterogeneous agent models in economics and finance. In: Tesfatsion, L., Judd, K.L. (Eds.), Handbook of Computational Economics, 2. Elsevier, North Holland, pp. 1109-1186.

Hommes, C., Sonnemans, J., Tuinstra, J., van de Velden, H., 2008. Expectations and bubbles in asset pricing experiments. J. Econ. Behav. Org. 67, 116-133.

Hommes, C., in 't Veld, D., 2017. Booms, busts and behavioural heterogeneity in stock prices. J. Econ. Dyn. Control 80, 101-124.

Jegadeesh, N., Titman, S., 1993. Returns to buying winners and selling losers: Implications for stock market efficiency. J. Finance 48 (1), $65-91$.

Jegadeesh, N., Titman, S., 2001. Profitability of momentum strategies: An evaluation of alternative explanations. J. Finance 46 (2), 699-720.

Kahneman, D., 2013. Thinking, Fast and Slow. Farrar, Straus and Giroux, New York.

Kaustia, M., Alho, E., Puttonen, V., 2008. How much does expertise reduce behavioral biases? the case of anchoring effects in stock return estimates. Financial Management 37 (3).

Kirchler, M., Lindner, F., Weitzel, U., 2018a. Delegated decision making and social competition in the finance industry. Faculty of Economics and Statistics, University of Innsbruck. Working Papers 2018-07, revised Sep 2018.

Kirchler, M., Lindner, F., Weitzel, U., 2018b. Rankings and risk-taking in the finance industry. J. Finance 73 (5), $2271-2302$.

König, C., Trautmann, S.T., 2018. Countercyclical risk aversion: Beyond financial professionals. J. Behav. Exp. Finance 18, 94-101.

Landier, A., Ma, Y., Thesmar, D., 2017. New experimental evidence on expectations formation. Working Paper. Harvard University.

List, J.A., 2003. Does market experience eliminate market anomalies? Q. J. Econ. 118 (1), 41-71.

List, J.A., 2004. Neoclassical theory versus prospect theory: Evidence from the marketplace. Econometrica 72 (2), $615-625$.

Loewenstein, G.F., Prelec, D., 1993. Preferences for sequences of outcomes. Psychol. Rev. 100, 91-108.

Menkhoff, L., Schmeling, M., 2013. Are all professional investors sophisticated? German Econ. Rev. 11 (4), $418-440$.

Oechssler, J., Roider, A., Schmitz, P.W., 2009. Cognitive abilities and behavioral biases. J. Econ. Behav. Org. 72, 147-152.

Pikulina, E., Renneboog, L., Tobler, P.N., 2017. Overconfidence and investment: an experimental approach. J. Corp. Finance 43, $175-192$.

Roszkowski, M.J., Snelbecker, G.E., 1990. Effects of "framing" on measures of risk tolerance: financial planners are not immune. J. Behav. Econ. 19 (3), 237-246.

Sheffer, L., Loewen, P.J., Soroka, S., Walgrave, S., 2018. Nonrepresentative representatives: an experimental study of the decision making of elected politicians. Am. Polit. Sci. Rev. 112 (2), 302-321.

Sirri, E.R., Tufano, P., 1998. Costly search and mutual fund flows. J. Finance 53 (5), 1589-1622.

Smith, V., Walker, J., 1993. Monetary rewards and decision cost in experimental economics. Econ. Inquiry 31 (2), $245-261$.

Thaler, R.H., Sunstein, C.R., 2008. Nudge: Improving Decisions About Health, Wealth, and Happiness. Yale University Press New Haven \& London.

Thoma, V., White, E., Panigrahi, A., Strowger, V., Anderson, I., 2015. Good thinking or gut feeling? cognitive reflection and intuition in traders, bankers and financial non-experts. PLoS One 10 (4).

Toplak, M.E., West, R.F., Stanovich, K.E., 2011. The cognitive reflection test as a predictor of performance on heuristics-and-biases tasks. Memory Cognit. 39 (7), 1275-1289.

Tversky, A., Kahneman, D., 1981. The framing of decisions and the psychology of choice. Science 211, 453-458.

Tversky, A., Kahneman, D., 1986. Rational choice and the framing of decisions. J. Busin. 59, 251-278.

Weitzel, U., Huber, C., Huber, J., Kirchler, M., Lindner, F., Rose, J., 2018. Bubbles and financial professionals. Faculty of Economics and Statistics, University of Innsbruck. Working Papers 2018-04, revised Oct 2018.

Ziegler, F.V., Tunney, R.J., 2015. Who's been framed? Framing effects are reduced in financial gambles made for others. BMC Psychol. 3 (9), 1-6. 